\title{
ANILLOS VERDES: ALGUNAS EXPERIENCIAS EUROPEAS
}

\author{
Itziar Aguado \\ Departamento de Geografía, Prehistoria y Arqueología. Universidad del País Vasco (UPV/EHU) \\ itziar.aguado@ehu.eus \\ Jose M. Barrutia \\ Departamento de Economía Financiera II. Universidad del País Vasco (UPV/EHU) \\ josemaria.barrutia@ehu.eus \\ Carmen Echebarria \\ Departamento de Economía Aplicada I. Universidad del País Vasco (UPV/EHU) \\ carmen.etxebarria@ehu.eus
}

\section{RESUMEN}

Los recientes cambios en los procesos urbanos están aumentando la expansión descontrolada de las ciudades y sus consecuencias negativas en términos de sostenibilidad. La tendencia no es tan visible en Europa como en otras regiones del mundo, pero podemos encontrar abundantes ejemplos de las presiones sufridas por los paisajes ubicados en las periferias urbanas. Este artículo se centra en el estudio de las prácticas de Anillos Verdes en Europa, un concepto de planificación que respeta la mezcla de usos rurales y urbanos y conlleva numerosos beneficios ecológicos. Con este objetivo, hemos seleccionado algunos estudios de caso europeos que han sido exitosos y presentamos el perfil de cada Anillo Verde, describiendo su contexto y el enfoque de planificación seguido. Para ello, el artículo está estructurado en tres grandes apartados: (1) un estudio histórico-conceptual que establece el marco teórico que subyace bajo la idea de los anillos verdes, (2) un análisis descriptivo de los casos seleccionados, y (3) un análisis cualitativo de los resultados de la aplicación de cada caso. Por último, se concluye con una discusión de los resultados y recomendaciones para el desarrollo futuro de los anillos verdes.

Palabras claves: Anillos verdes, sostenibilidad, expansión urbana e infraestructuras verdes urbanas.

Fecha de recepción: enero 2015.

Fecha de aceptación: octubre 2016. 


\section{ABSTRACT}

Recent changes in the urban processes are increasing the sprawl of the cities and its negative consequence in terms of sustainability. The trend is not so visible in Europe than in other regions, but we can find copious examples of pressures on landscapes located in the fringe of the cities. This paper focuses on greenbelt practices in Europe, a planning concept which respects the mixture of urban and rural land uses and endorses numerous ecological benefits. With this aim, we have selected some successful European case studies in the developing of these instruments and a profile of each greenbelt is presented describing its background and its planning approach. Thus, the paper has three major parts: (1) a historicalconceptual study that establishes the framework that lies behind the idea of Greenbelt; (2) several descriptive study-case analysis; and (3) a qualitative analysis of the outcomes of the implementation of each case. Finally, we conclude with a discussion of the results and recommendations for the future development of green belts.

Keywords: Green belts, sustainability, urban sprawl and urban green infrastructure.

\section{INTRODUCCIÓN}

Estamos siendo testigos de cómo las ciudades y el planeamiento urbano actual, poco coherente con los principios que rigen la sostenibilidad, generan una serie de impactos negativos en la calidad del paisaje y en el territorio. Más aún, la expansión desordenada de las ciudades, con nuevos modelos de urbanismo monofuncionales en forma de mancha difusa que se extiende por el territorio, está contribuyendo a agravar los diversos problemas medioambientales y sociales que padecen estas áreas como son la contaminación atmosférica, acústica y lumínica, el inadecuado suministro de servicios, la proliferación de barrios dormitorio, el aumento del tráfico y la movilidad forzada, entre otros (Bengston, 2005).

Con el fin de que las ciudades sean sostenibles y ecológicamente viables, se debe replantear y reorganizar su funcionamiento superando políticas sectoriales y proponiendo actuaciones integrales que consideren tanto las variables ambientales como las económicas y sociales. Hay que tender hacia modelos de ciudades con un metabolismo circular, donde el consumo de materias primas y energía se reduzca al mínimo, y donde se cierren los ciclos, persiguiendo que los residuos que la ciudad genere puedan ser reutilizados en el sistema de producción, reduciendo así su huella ecológica (Williams et al., 2001; Brabec y Lewis, 2002).

Por otro lado, el paisaje urbano muchas veces es excluido de la protección paisajística, al considerarse un espacio artificial donde no existen valores ecológicos a conservar. Sin embargo, el funcionamiento de las ciudades es clave para entender la crisis ecológica actual tanto en su dimensión local como global. Se estima que las ciudades contribuyen en más de un $75 \%$ a la contaminación global del planeta y suponen el 70\% de la energía consumida. También hay que considerar que son precisamente las ciudades las que tienen un mayor potencial para afrontar esta crisis, ya que son focos de innovación y de difusión y aglutinan un gran potencial humano. Se deben, por tanto, cambiar los paradigmas de 
hacer ciudad, superando el cortoplacismo y los patrones insostenibles de expansión de las ciudades. Y es aquí donde el aprendizaje de experiencias exitosas puede proporcionar una serie de propuestas que permitan transitar en el camino hacia la sostenibilidad.

Estos impactos negativos son especialmente visibles en las áreas periurbanas debido a la aceleración de los procesos de suburbanización. La mayor presión demográfica conlleva el incremento de demanda de suelo para viviendas. También es preocupante el progresivo consumo de suelo para un creciente número de infraestructuras, lo que contribuye a una mayor fragmentación de los hábitats naturales con las consiguientes repercusiones negativas sobre la fauna y la flora. Como resultado, se constata una fuerte reducción de la biodiversidad de las zonas de borde de ciudad, de los espacios de ocio próximos para el disfrute de la población y de las tierras agrícolas de calidad.

Como respuesta a todo ello, algunas voces exigen una mejor conservación de estas áreas periurbanas y el fomento de una planificación adecuada a sus características y a su fragilidad. Aspectos como el tamaño, la forma y el aislamiento de los espacios naturales o seminaturales deben tenerse en cuenta para determinar los impactos en los procesos ecológicos y en la diversidad de especies. Todo ello está íntimamente ligado al mantenimiento de una forma urbana compacta como modelo de ciudad más sostenible (Burton, 2000; Blais, 2010). Una ciudad compacta genera un mejor aprovechamiento de los recursos, permite un modelo de movilidad basado en el peatón, fomenta una mayor interacción social y una sociedad más diversa y facilita un mejor acceso a equipamientos y servicios públicos (Comisión de las Comunidades Europeas, 1990; Thomas y Cousins, 1996; Rueda, 2002).

Los anillos verdes constituyen un instrumento de planificación urbana con una gran trayectoria en la lucha contra el sprawl de las ciudades (Siedentop et al., 2016). Se han venido utilizando para generar múltiples beneficios sociales y ambientales, entre los que se pueden citar la protección de zonas verdes y espacios naturales, la conservación de tierras agrícolas, la creación de zonas de esparcimiento y ocio para la población urbana, la conservación de la biodiversidad y del paisaje, la preservación de valores culturales, etc. En los últimos tiempos están adquiriendo además nuevas funciones como la lucha contra el cambio climático, la reducción de diversos riesgos ambientales (incendios e inundaciones, principalmente) o la educación y sensibilización ambiental (Yokohari et al., 2000; Yang y Jinxing, 2007; Brown et al., 2004; Kahn y Abbasi, 2000; Mortberg y Wallentinus, 2000).

En consecuencia, nuestra intención en este artículo es conocer cómo se está aplicando este concepto en el planeamiento europeo. Para ello, analizaremos una serie de actuaciones europeas que aplican este tipo de instrumento, fijándonos en cuestiones tales como la extensión del proyecto, los organismos promotores, las actuaciones acometidas, etc., con el propósito de identificar factores relevantes a la hora de poner en marcha este tipo de prácticas urbanísticas.

La metodología utilizada se basa en el estudio de buenas prácticas a partir de un análisis comparativo inicial de diferentes actuaciones de Infraestructuras Verdes a nivel internacional. Las buenas prácticas son herramientas útiles de cara al aprendizaje y la réplica de experiencias exitosas en otros contextos, por lo que esta metodología se presenta especialmente apropiada para el estudio de los paisajes urbanos y su gestión sostenible. 
Para llevar a cabo la investigación hemos procedido del siguiente modo:

- En primer lugar, se realiza una revisión de la literatura relativa al concepto de Anillos Verdes, analizando tanto artículos científicos publicados en revistas de reconocido prestigio internacional como documentación publicada por entidades promotoras de distintas iniciativas de Anillos Verdes (Autoridades Locales, Agencia Europea de Medio Ambiente (AEMA), Greenbelt Foundation, etc.). También, se ha realizado una búsqueda y síntesis de los documentos gubernamentales que atañen a su gestión y planificación. Esta revisión de la literatura nos ha permitido conocer los antecedentes históricos y delimitar el concepto y su funcionalidad.

- A continuación, se recopila un banco de ejemplos europeos de Anillos Verdes, a través de la selección y estudio sistemático de experiencias innovadoras, al tiempo que se realiza un análisis crítico de los estudios de caso seleccionados intentando poner de manifiesto los aspectos fundamentales para que estas prácticas sean exitosas. Nos fijamos en aspectos como la entidad promotora, las actuaciones acometidas, la gestión y planificación, etc.

- Por último, se pretende dilucidar cuáles son los elementos básicos que permiten medir su grado de éxito para poder establecer una serie de recomendaciones a tener en cuenta en la planificación de este instrumento.

\section{ANTECEDENTES HISTÓRICOS}

La ciudad sostenible, como hemos comentado, a menudo se ha identificado con una ciudad compacta, una densidad alta y una mezcla de usos (Brown et al., 2004). Esa compacidad estaba asegurada antes de la Revolución Industrial, puesto que las restricciones que imponían los medios de transporte de la época impedían la expansión de las ciudades. Con el paso del tiempo y el incremento de la población tras el cambio de régimen demográfico, las ciudades aumentaron su densidad agravando las pésimas condiciones de vida preexistentes. Tras el derribo de las murallas en la mayoría de ciudades de Europa durante los siglos XVIII y XIX, los espacios libres que dejaron fueron destinados a la creación de paseos y zonas de recreo con el objetivo de mejorar la calidad de vida de los habitantes y reverdecer las contaminadas ciudades industriales. Aunque no podamos considerar estos espacios como Anillos Verdes, sí que podemos apreciar algunas coincidencias, dado que estas zonas se establecieron como instrumentos de planificación para separar la ciudad construida del área rural colindante, al tiempo que proporcionaban un área recreativa a la ciudadanía (Kühn, 2003).

Diversos autores (Freestone, 2002; Bengston y Youn, 2006; Yokohari et al., 2000; Yang y Jinxing, 2007), aseguran que el origen de los Anillos Verdes se encuentra en las propuestas realizadas por Ebenezer Howard a finales del siglo XIX (Howard, 1898). Próximo a los ideales del utopismo reformista, consideraba que las ciudades de la época estaban sobredimensionadas y sus condiciones de vida eran pésimas. Para superar estos problemas, Howard proponía, en su plan de ciudad jardín, que la descongestión de las grandes ciudades se hiciese mediante ciudades jardín, células urbano-rurales rodeadas de cinturones verdes que permitirían combinar los beneficios tanto de las áreas rurales como urbanas y 
evitar los aspectos negativos de ambas. Estos cinturones preservaban una zona no desarrollada en torno a los centros urbanos al tiempo que servían para controlar el crecimiento de la ciudad, imponiendo unos límites físicos a la misma (Dawkins y Nelson, 2002).

Las ciudades jardín se encontraban rodeadas de una zona agrícola y para uso recreativo denominada cinturón verde. Este concepto que Howard incorporaba en su libro "Garden Cities of Tomorrow" (1902) era el de un instrumento para contener el crecimiento urbano utilizando las áreas rurales circundantes (Yokohari et al., 2000; Biles, 1998). Su visión, planteaba una franja de tierra que incluyese bosques, tierras agrícolas y otras áreas naturales y que sirviese para separar unas ciudades de otras y preservar esos espacios naturales. Basándose en la tradición planificadora de la época, no sólo consideraba aspectos físicos, sino que abarcaba cuestiones sociales. Pretendía construir sociedades autosuficientes que pudieran enfrentarse a los problemas de las ciudades industriales de la época, como eran los elevados alquileres y precios de las viviendas, la contaminación, la escasez de espacios verdes, etc.

A nivel local, se materializaron algunas iniciativas siguiendo el modelo propuesto por Howard como, por ejemplo, las ciudades de Welwyn y Letchworth en el Reino Unido o Radburn en los Estados Unidos. Pero el esfuerzo más notable en esta dirección fue la introducción de estas ideas en el ámbito de la planificación regional. La primera propuesta gubernamental fue lanzada por la Comisión de Planificación Regional para el Gran Londres en el año 1935, con el objetivo de proporcionar una reserva de espacios públicos y áreas recreativas. Esta propuesta fue implementada por primera vez en la práctica en Londres con la aplicación de la Ley de Cinturones Verdes aprobada en 1938 (The Green Belt Act), y, posteriormente, con el Plan del Gran Londres de 1943, conocido como el Plan Abercrombie, y la Ley de Planificación Regional y Urbana de 1947 (The 1947 Town and Country Planning Act). Rápidamente se extendió a otras ciudades del Reino Unido y el Plan de Abercrombie sirvió de modelo para ciudades como Estocolmo, Helsinki, Seúl y Ottawa (Gordon y Scott, 2008). Con posterioridad, se propagó al resto del mundo con una importante aplicación en las Colonias Británicas (Sorensen, 2001; Yang y Jinxing, 2007; Jun, 2012).

A partir de esa fecha, han sido numerosos los ejemplos de Anillos Verdes o infraestructuras verdes periurbanas puestas en marcha en todo el mundo (el Cinturón Verde de Moscú, el Plan de los Dedos de Copenhague, el Cinturón Verde de Ottawa, el Green Heart de los Países Bajos, etc.), unos con más éxito que otros, pero todos ellos bajo los mismos principios generadores: mitigación de las presiones del crecimiento urbano y las infraestructuras asociadas a éste, dotación de áreas verdes y de esparcimiento próximas a la ciudad, búsqueda de la implicación ciudadana, recuperación de áreas degradadas o frágiles y conservación de la biodiversidad de la zona.

\section{DELIMITACIÓN DEL CONCEPTO Y FUNCIONALIDAD}

Es necesario señalar que el concepto de Anillo Verde no presenta un sentido definido único al agrupar una pluralidad de significaciones y tipologías que se enmarca en una reflexión general sobre los espacios libres o verdes frente al crecimiento urbano sin límite 
(Labidoire, 2013). Los Anillos Verdes no son instrumentos estáticos sino que han ido adaptándose y evolucionando hasta dar lugar a prácticas muy vigentes en la actualidad como serían las infraestructuras verdes urbanas (Ahern, 2007; Benedict y McMahon, 2002, 2006; Comisión Europea, 2009). La forma clásica de los cinturones verdes es el de un anillo de espacios abiertos que rodea la ciudad, aunque con frecuencia puede adquirir formas irregulares en función de las características geográficas de la zona (Ali, 2008). En un intento bastante exitoso de delimitar su significación y evolución, Freestone (2002: 68-69) realiza una tipología de diferentes instrumentos de planificación que subyacen bajo el concepto de Anillos Verdes (parklands, ciudad jardín, cinturón de parques, franjas verdes, vías arboladas, vías verdes, redes verdes, cuñas verdes, corredores verdes, ciudades ecológicas, etc.) y los relaciona con las políticas urbanas y los objetivos de calidad ambiental que persiguen. No obstante, esta clasificación no es capaz de ofrecer una definición unívoca y clara del término debido a su carácter de espacio sometido a continuos cambios y presiones, de lugares de transición entre lo rural y lo urbano y de no constituir exclusivamente una pieza de la trama urbana, sino que mantienen una relación muy estrecha con la región en la que la urbe se inserta. De hecho, en este trabajo, basándonos en Freestone (2002), vamos a utilizar el término de anillos verdes como concepto paraguas que aglutinaría a morfologías dispares de infraestructuras verdes urbanas o periurbanas.

Hay que tener en cuenta que estas iniciativas se han desarrollado fundamentalmente en Europa, aunque también se encuentran varios ejemplos en Norteamérica y es cada vez una práctica más habitual en Asia, especialmente en torno a sus megaciudades para frenar la expansión urbana (Yokohari et al., 2000). Precisamente, en la mayoría de los casos, los Anillos Verdes se han propuesto con este fin y para promover un uso del suelo más sostenible pero, como algunos autores han sugerido, un cinturón verde por sí solo no puede detener el crecimiento de la superficie urbanizada (Hall et al., 1973; Mills, 2002; Pendall et al., 2002). Por esa razón, es importante centrarse también en las otras funciones que estas infraestructuras verdes pueden cumplir (véase Tabla 1) y apoyar este tipo de prácticas con otras herramientas dentro de un paquete integral de medidas.

En esta evolución también se han ido superponiendo una serie de funciones y objetivos. Así, la función inicial era asegurar espacios libres para una agricultura de proximidad a las áreas urbanas (Akimowicz et al., 2016) y para limitar el crecimiento urbano y preservar las áreas rurales (Yang y Jinxing, 2007). No obstante, las funciones que cumplen los Anillos Verdes en la actualidad han cambiado y cada vez son más significativas (Bengston y Youn, 2006; Amati y Yokohari, 2006). En este sentido, puede señalarse que proporcionar seguridad alimentaria, proteger la integridad ecológica del área, conservar la biodiversidad, preservar la calidad del agua local o dotar de espacios naturales para actividades recreativas y de ocio a zonas próximas a los núcleos urbanos, son, entre otros, algunos de los objetivos que este tipo de infraestructuras verdes tratan de alcanzar. Además, los servicios ecosistémicos que aportan también pueden contribuir a mejorar la salud física y mental de los ciudadanos (Tzoulas et al., 2007). 
Tabla 1

MARCO CONCEPTUAL DE LOS ANILLOS VERDES

\begin{tabular}{|c|c|c|}
\hline Casos analizados & Forma y Evolución & Funciones \\
\hline $\begin{array}{l}\text { Adelaide, Perth, Camberra, } \\
\text { Frankfurt, Düsseldorf, } \\
\text { Hanover, Mittelhessen } \\
\text { (Alemania), Stuttgart, } \\
\text { Vancouver, Portland, } \\
\text { Doncaster, Harrisburg, } \\
\text { Raleigh, Londres, Boston, } \\
\text { Copenhagen, Letchworth, } \\
\text { Vienna, Calgary, Ottawa, } \\
\text { Saskatoon, Toronto, Topeka } \\
\text { (Kansas), Montgomery } \\
\text { County, Chicago, Florida } \\
\text { Greenways, Pittsford } \\
\text { (Nueva York), Pekín, Tokyo, } \\
\text { Seúl, Bangkok, Londres, } \\
\text { Shanghai, Calgary, Ottawa, } \\
\text { Saskatoon y Bilbao. }\end{array}$ & $\begin{array}{l}\text { - Concepto paraguas que evoluciona } \\
\text { desde el siglo XIX y deriva en } \\
\text { espacios verdes de diferente tipología } \\
\text { (Parklands, Garden City, Parkbelts, } \\
\text { Green girdles, Parkways/greenwebs, } \\
\text { Green backcloth, Greenbelt City, Green } \\
\text { wedges/corridors, Regional City, } \\
\text { Greenways, Green zones, Ecological } \\
\text { cities, Green infrastructure) (véase } \\
\text { Freestone, 2002) } \\
\text { - Equiparables con los Greenways con } \\
\text { quienes comparten los objetivos de } \\
\text { conservación y conectividad, pero no se } \\
\text { basan tanto en la linealidad. } \\
\text { - Posible evolución hacia redes e } \\
\text { infraestructuras verdes que pretenden } \\
\text { una mayor conexión con el sistema } \\
\text { verde urbano y con los hábitats } \\
\text { naturales. } \\
\text { - Amplia diversidad que va desde } \\
\text { estrechas franjas perimetrales que } \\
\text { delimitan el núcleo urbano hasta } \\
\text { amplias áreas verdes que incluyen el } \\
\text { espacio rural. }\end{array}$ & $\begin{array}{l}\text { - Contención del crecimiento. } \\
\text { - Protección de tierras agrícolas. } \\
\text { - Elemento separador entre } \\
\text { núcleos urbanos o entre el } \\
\text { campo y la ciudad. } \\
\text { - Dotación de zonas verdes } \\
\text { y naturales de proximidad, } \\
\text { incremento de la oferta } \\
\text { recreativa. } \\
\text { - Restauración del hábitat. } \\
\text { - Funciones ecológicas (control } \\
\text { de inundaciones, mejora de la } \\
\text { calidad del aire). } \\
\text { - Conservación de la fauna y flora. } \\
\text { - Conectividad con otros sistemas } \\
\text { ecológicos. } \\
\text { - Contribuir a la mejora de la } \\
\text { salud ciudadana (reducción } \\
\text { del estrés, mejora del medio } \\
\text { urbano, reducción de problemas } \\
\text { respiratorios, etc.) }\end{array}$ \\
\hline
\end{tabular}

Fuente: elaboración propia en base a Yokohari et al. (1994), Taylor et al. (1995), Benedict y McMahon (2002), Freestone (2002), Amati y Yokohari (2006), Yang y Jinxing (2007), Breiling y Ruland (2008), Casado-Arzuaga et al. (2013), Labidoire (2013), Siedentop et al. (2016) y Akimowicz et al. (2016).

En definitiva, continúa siendo una herramienta de planeamiento relevante (Amati, 2008), aunque también en los últimos años ha sido objeto de algunas críticas debido a que puede generar una serie de efectos negativos como los que, desafortunadamente, se han hecho visibles en algunas ciudades dando lugar, precisamente, a los efectos contrarios a los que se persigue con su implantación (Watanabe et al., 2008; Kim y Kim, 2008). Su contribución positiva está ligada al cumplimiento de los múltiples objetivos con los que son planificados, pero habrá que considerar que no es un instrumento apropiado para todas las ciudades y que, en determinadas circunstancias, los efectos negativos pueden superar a los positivos (véase Tabla 2). Entre otros, puede provocar nuevos desarrollos urbanísticos más allá de los límites de los anillos verdes lo que implicará unos mayores costes de transporte y de dotación de servicios públicos (Bengston y Youn, 2006; Siedentop et al., 2016). También puede producir un incremento del precio de la vivienda, al no permitir generar una oferta suficiente en correlación con los posibles incrementos de la demanda (Kim, 1990; Evans, 2006). En esta línea, provocaría una paralización de la economía, tanto en el sector inmobiliario al reducirse la compra-venta de viviendas, como en el sector comercial al incrementar los costes de instalación de los comercios y servicios (Cox, 2004). 
Tabla 2

VALORACIÓN DE LOS ANILLOS VERDES COMO INSTRUMENTO DE PLANIFICACIÓN URBANA

\begin{tabular}{|c|c|c|}
\hline Casos analizados & Aspectos positivos & Aspectos negativos \\
\hline $\begin{array}{l}\text { Seúl, Moscú, } \\
\text { Santiago, } \\
\text { Londres, Seúl, } \\
\text { Ottawa, Toronto, } \\
\text { Tokyo, Bangkok, } \\
\text { Pekín, Berlín, } \\
\text { Hong Kong, } \\
\text { Vitoria-Gasteiz, } \\
\text { Düsseldorf, } \\
\text { Hannover, } \\
\text { Mittelhessen, } \\
\text { Stuttgart. }\end{array}$ & $\begin{array}{l}\text { - Conservación del legado } \\
\text { histórico y los valores } \\
\text { patrimoniales. } \\
\text { - Ahorros fiscales debido a } \\
\text { una mayor eficiencia en } \\
\text { la prestación de servicios } \\
\text { públicos e infraestructura, } \\
\text { y una amplia gama de } \\
\text { servicios ambientales. } \\
\text { - Protección de especies } \\
\text { amenazadas. } \\
\text { - Lucha contra el cambio } \\
\text { climático. } \\
\text { - Mejoras en la calidad del } \\
\text { aire. } \\
\text { - Conservación de la vida } \\
\text { salvaje. } \\
\text { - Mejora de la calidad y } \\
\text { cantidad de agua. } \\
\text { - Sensibilización ambiental. }\end{array}$ & $\begin{array}{l}\text { - Encarecimiento del precio de la vivienda. } \\
\text { - Fomento de una mayor dispersión urbana si } \\
\text { se produce el efecto leapfrog (surgimiento de } \\
\text { manchas urbanas discontinuas exteriores al } \\
\text { Anillo Verde). } \\
\text { - Incremento del tráfico motorizado. } \\
\text { - Puede repercutir en un déficit de } \\
\text { infraestructuras. } \\
\text { - Conflicto entre la conservación de la fauna y } \\
\text { la oferta recreativa. } \\
\text { - No es capaz de contener el crecimiento de la } \\
\text { ciudad. } \\
\text { - Son construcciones abstractas realizadas } \\
\text { por planificadores que no tienen siempre en } \\
\text { cuenta las características locales ni los usos } \\
\text { sociales. } \\
\text { - Pueden constituir zonas de transición en } \\
\text { lugar de conservación. } \\
\text { - Posibles consecuencias económicas } \\
\text { negativas. } \\
\text { - Pérdida de empleos por los altos precios del } \\
\text { suelo si hay fuertes restricciones en los usos } \\
\text { del suelo. } \\
\text { - Incremento del gasto público cuando se } \\
\text { ofrecen compensaciones a los agricultores } \\
\text { por las restricciones de uso y la pérdida de } \\
\text { plusvalías del suelo. }\end{array}$ \\
\hline
\end{tabular}

Fuente: elaboración propia en base a Yokohari et al. (2000), Kühn (2003), Cox (2004), Bengston y Youn (2006), Evans (2006), Blinnikov (2007), Yang y Jinxing (2007), Tang et al. (2007), Campbell (2009), Aguado et al. (2013) y Siedentop et al. (2016).

\section{ALGUNAS EXPERIENCIAS EN EUROPA}

En los próximos apartados, vamos a analizar una serie de ejemplos de Anillos Verdes puestos en marcha en Europa, atendiendo, principalmente, a aspectos tales como la estructura jurídica, los mecanismos y niveles de protección existentes, las administraciones involucradas en la gestión, los rasgos característicos de la zona (valores naturales y culturales, relación con los núcleos urbanos, tamaño, etc.), las presiones a las que están sometidos, los retos futuros, etc.

Hemos decidido seleccionar exclusivamente casos europeos por ser la región con una mayor trayectoria y difusión de este tipo de instrumentos. Se ha optado por cinco casos (Londres, Copenhague, Colonia, Frankfurt y Bruselas) de diferente antigüedad y escala y 
con planteamientos muy diferentes en su concepción, considerando que las lecciones aprendidas de estos ejemplos pueden proporcionar un marco útil para la planificación del paisaje y el desarrollo de futuros anillos e infraestructuras verdes. Inicialmente, se puede apreciar que aunque el ámbito de aplicación, los métodos de planificación, la forma y el contexto administrativo de cada caso analizado sean diferentes, todos ellos presentan características comunes como son la búsqueda de una mejor conservación de los espacios verdes y de una mayor conectividad de las zonas urbanas con el entorno natural y rural.

\section{IV.1. El Anillo Verde del Área Metropolitana de Londres}

El Gran Fuego de Londres de 1666 provocó que la ciudad creciese más allá de la muralla medieval, continuando con esa constante expansión hasta la década de 1930. Con el objetivo de proteger las áreas rurales periféricas de la ciudad, se aprobó la Ley del Cinturón Verde de 1938 (The 1938 London and Home Counties Green Belt Act) -en aplicación de la política de Anillos Verdes adoptada en 1935 por el Comité de Planificación Regional del Gran Londres-, que pretendía poner fin a la creciente expansión suburbana mediante la creación de un cordón verde alrededor de Londres (Amati, 2007; Cohen, 1994; Munton, 1983).

Los desarrollos urbanísticos en el interior del cinturón verde son muy restrictivos y toda propuesta de urbanización debe demostrar un beneficio real que compense la pérdida de áreas verdes. Con la limitación al crecimiento de la ciudad que imponía el Cinturón Verde, se previó que la población que Londres no pudiese absorber tuviera cabida en nuevos núcleos independientes más allá de la zona verde fijada. El plan tuvo un gran éxito, debido a una legislación de control urbanístico muy estricta y la idea de cinturón verde fue ampliamente extendida en Gran Bretaña (Millward, 2006). Como resultado de ello, gran parte del exterior de Londres sigue siendo un mosaico de paisajes rurales y pequeños pueblos (Ween, 2012).

El Anillo Verde quedó finalmente consolidado en 1947 mediante la Town and Country Planning Act. En 1954, se constituyó el Consejo del Anillo Verde de Londres, órgano consultivo creado con el fin de asesorar y revisar las actuaciones desarrolladas en el marco del Anillo Verde. Tanto el Departamento de Comunidades y Gobierno Locales como el Departamento de Medio Ambiente, Alimentación y Asuntos Rurales ostentan la responsabilidad principal en cuanto a las políticas de planificación relativas al Anillo Verde, aunque también juegan un papel fundamental los consejos municipales, cuyos técnicos son quienes deciden sobre la conveniencia o no de permitir desarrollos urbanísticos en el cinturón verde. Aún así, las decisiones de mayor dimensión o controvertidas son tomadas por el Comité de Planificación del Consejo, que está compuesto por cargos políticos (Amati y Yokohari, 2006, 2007; Tallon, 2010: 35-36).

El Anillo Verde de Londres es el mayor de los catorce Anillos Verdes existentes en Gran Bretaña, con una superficie de 484.173 hectáreas, lo que supone el 3,7\% de la superficie de Gran Bretaña y un 30\% del área total correspondiente a Anillos Verdes (ver Figura 1). A través del mismo, se pretende ayudar a proteger el área rural de la urbanización, preservando su identidad y valores culturales. También se persigue fomentar la regeneración urbana, promoviendo la adecuación y aprovechamiento de espacios urbanos interiores que se encuentren en desuso. Otro de los objetivos perseguidos es el de proporcionar acceso a áreas naturales y de esparcimiento a las poblaciones urbanas (Natural England, 2010a, 2010b, 2011). 


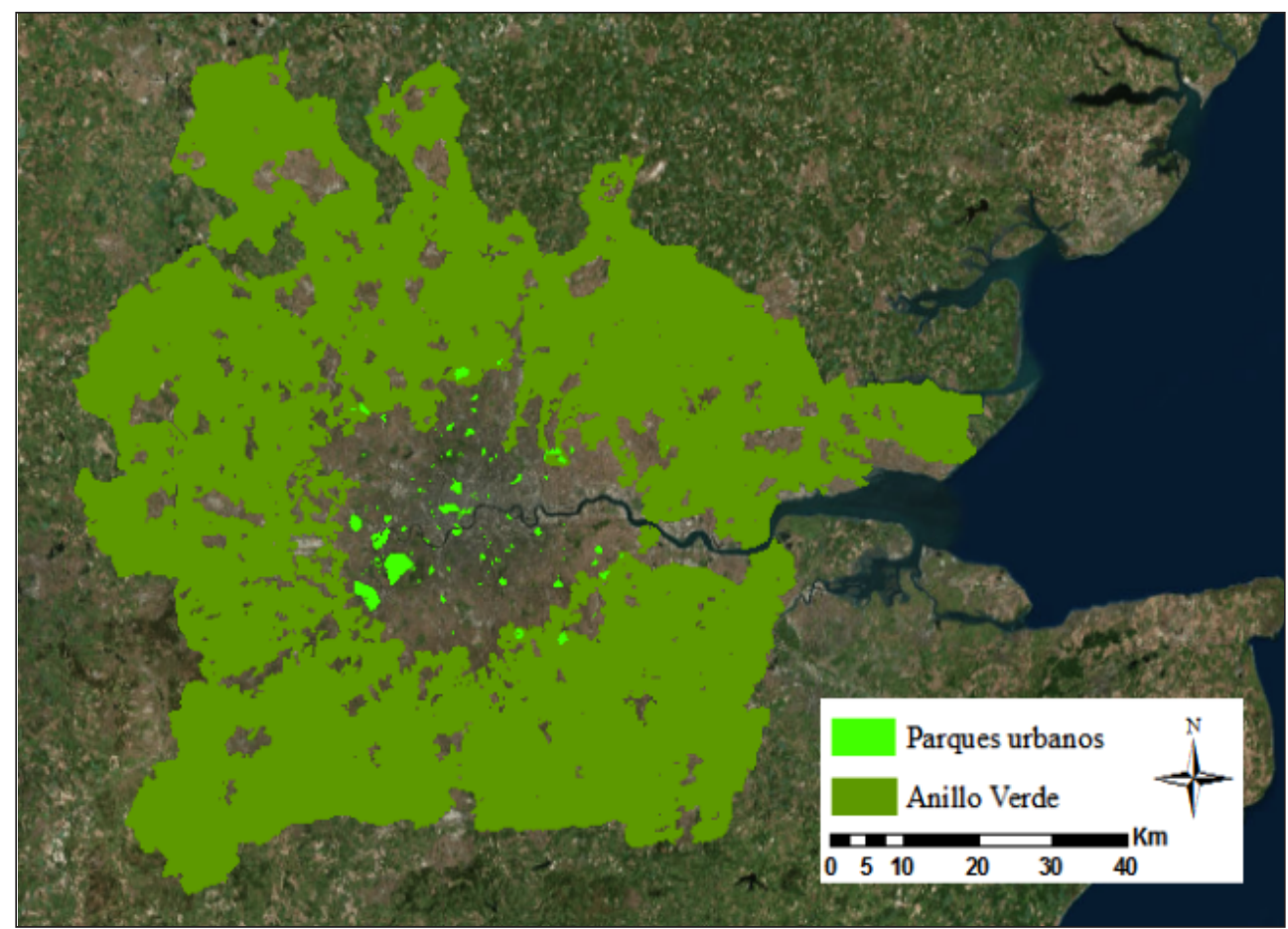

Fuente: elaboración propia mediante ARCGIS.

El Anillo Verde de Londres tiene además un claro interés conservacionista, buscando proteger el medio natural y otros suelos destinados a la agricultura, silvicultura y otros usos relacionados. De hecho, el 82\% de las tierras pertenecientes al Anillo Verde de Londres son agrícolas, encontrando una gran diversidad de paisajes agrarios (pastos, grandes extensiones de agricultura intensiva, tierras de cultivo de pequeña y mediana dimensión en las zonas de valle, etc.). Las áreas de mayor calidad paisajística corresponden a las zonas de bosque y de río, existiendo una superficie relativamente importante (119.561 hectáreas) designada como Áreas de Belleza Natural Sobresaliente (Areas of Outstanding Natural Beauty). De esta forma, aún tratándose de una zona especialmente afectada por presiones debidas tanto a nuevos desarrollos urbanos como a la implantación de infraestructuras de todo tipo, presenta una alta variedad de ecosistemas: ríos que fluyen a través de amplios valles, cinturones de árboles, áreas boscosas, tierras bajas con acantilados escarpados y praderas de alta calidad, bosques de coníferas, la llanura de inundación del río Támesis, etc. (Natural England, 2010b).

El cinturón verde queda definido como una "zona de no-desarrollo" rodeando la ciudad, que goza de la máxima protección y donde cualquier desarrollo urbanístico inapropiado es rechazado. Se le otorga el mismo nivel de protección que a los Espacios Libres Metropoli- 
tanos (Metropolitan Open Land-MOL-), animándose a las autoridades locales a establecer estrategias claras para la protección, promoción y gestión de la biodiversidad, la geodiversidad y el acceso a la naturaleza (Ween, 2012).

Las principales amenazas que afectan al desarrollo de esta área serían, como ya hemos comentado, los impactos generados por la creciente presión urbanística y la construcción de nuevas infraestructuras, así como el aeropuerto cercano y el abandono de las tierras de cultivo. Precisamente las zonas más frágiles son las zonas de borde. Aún así, el Anillo Verde constituye uno de los instrumentos más exitosos del sistema de ordenación territorial en relación al control del crecimiento urbano y a la protección de los usos no urbanos del suelo (Verdaguer, 2010), aunque también es cierto que existe un sentimiento entre los planificadores de que la planificación del cinturón verde es injusta, obsoleta e ineficiente, lo que ha dado lugar a una gran variedad de propuestas para su reforma (Amati y Yokohari, 2006). De hecho, desde hace más de sesenta años Londres viene aprobando diferentes planes de gestión y planificación de espacios libres, en los que se plantea la creación de corredores ecológicos para conectar amplias zonas pertenecientes al Anillo Verde a través de corredores lineales. En esta línea, la Estrategia Verde de 1991 se centró en la creación de una serie de redes verdes superpuestas para favorecer la conectividad verde y favorecer la diversidad biológica (Turner, 2006; Tan, 2006).

\section{IV.2. El Plan de los Dedos de Copenhague}

En Copenhague se ha diseñado una estructura verde, similar a los Anillos Verdes, que pretende actuar a modo de muro de contención frente a los procesos de dispersión urbana. Cuenta con una extensión de 10.900 hectáreas y fue auspiciada a través del conocido como Plan de los Dedos de 1947, que tiene rango de ley, a partir de la Ley de Planificación de Dinamarca de 2007. Esta ley, de aplicación en la Región del Gran Copenhague, establece como principios orientadores que los desarrollos urbanos tanto en la región central como periférica (la conocida como "ciudad de los dedos") deben fortalecer el sistema de transporte público y la preservación de las cuñas verdes de desarrollos urbanísticos (Carter-Whitney y Esakin, 2010).

$\mathrm{Su}$ peculiaridad radica en su forma característica de mano, en el que la "palma de la mano" se ubicó en el centro de la ciudad ya existente y los dedos señalaban el futuro desarrollo de la ciudad a lo largo de la infraestructura de transporte existente. Este diseño surgió derivado del propósito de canalizar el crecimiento de la ciudad en forma radial para favorecer una mejor movilidad urbana y permitir a los residentes disponer de áreas verdes de proximidad. Además, de este modo, se protegía de la expansión urbana a las zonas rurales y naturales.

En Dinamarca, si bien es el Gobierno Nacional quien determina los principios generales de la planificación, son los propios municipios quienes deben regular el uso del suelo en las zonas rurales y urbanas, así como desarrollar las medidas protectoras de las áreas naturales. Los planes municipales dan forma concreta a las estrategias y actuaciones a incorporar en el planeamiento urbano local. No obstante, una de las debilidades que presenta es que no se ha establecido una protección específica para los paisajes agrícolas, lo que está derivando en un significativo declive de las tierras de cultivo (ver Figura 2). 


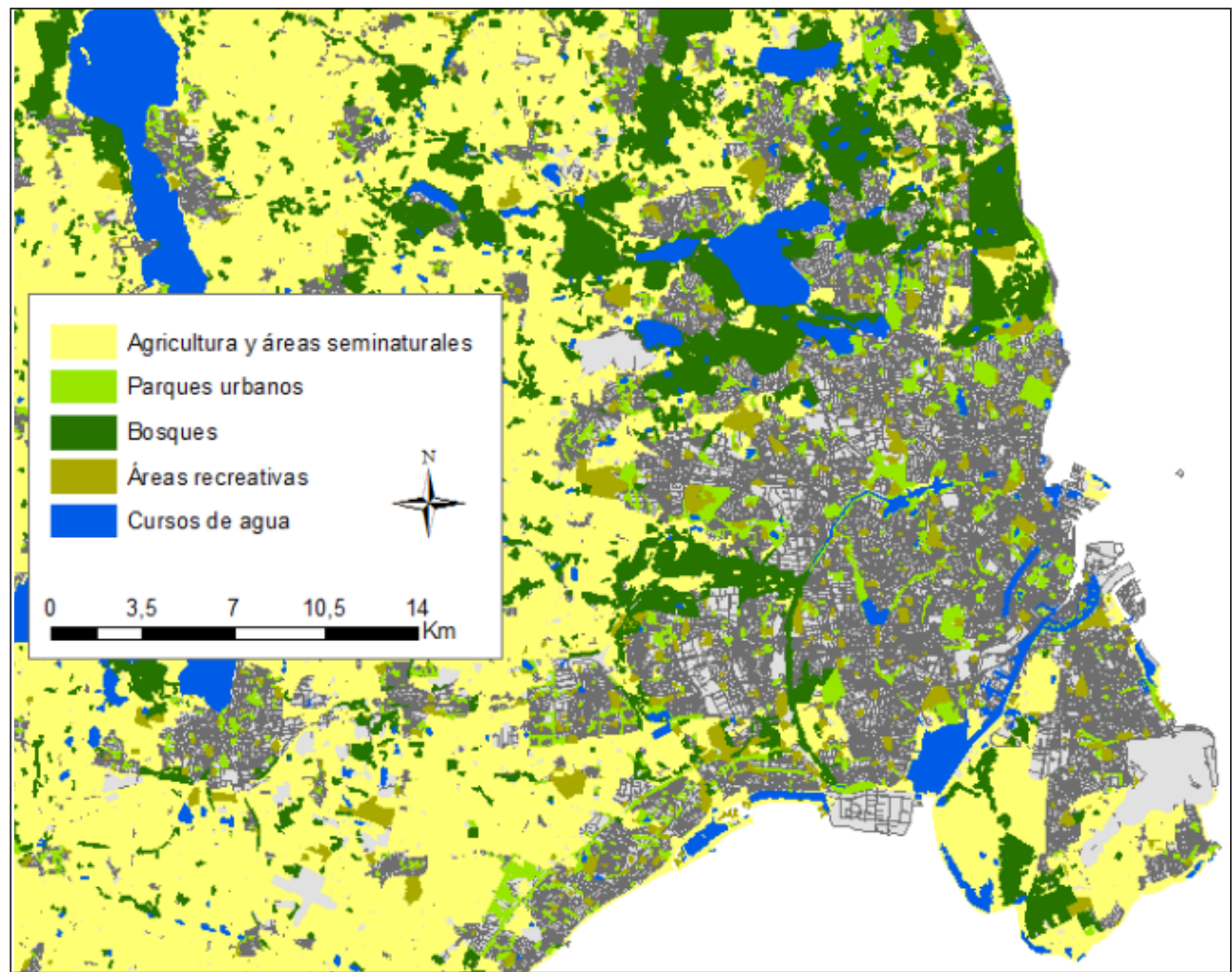

Fuente: elaboración propia mediante ARCGIS en base a información cartográfica del European Urban Atlas.

Dado que las competencias de planificación están traspasadas a los municipios y no han de contar, como previamente era necesario, con el visto bueno de la autoridad regional, éstos desempeñan un papel primordial en asegurar que sus planes son coherentes con el Plan de los Dedos. En este sentido, el Plan no está exento de controversia puesto que existen municipios, por lo general con un desarrollo urbanístico ya consolidado, que apoyan el Plan, mientras que, por otra parte, se oponen al mismo los municipios limítrofes a las cuñas verdes y que cuentan todavía con espacio libre para urbanizar al ver reducida su capacidad para futuros desarrollos urbanísticos. Asimismo, los propietarios privados también se oponen, mayoritariamente, al proyecto dado que ven como sus tierras están sujetas a restricciones sobre la construcción y los cambios en la cubierta vegetal. De ahí, que conseguir su compromiso con el proyecto ha sido y sigue siendo fundamental para el logro de los objetivos del Plan de los Dedos.

Además de las cuñas verdes, el Plan de los Dedos de 2005 introdujo la constitución de un Anillo Verde para proporcionar una conexión entre los bosques, los lagos y las regiones naturales del norte de Copenhague con las áreas naturales occidentales y las playas del sur. 
En estas zonas no se permiten nuevos desarrollos urbanísticos dándose prioridad a los usos recreativos no urbanos como espacios naturales, campos deportivos y campos de golf. En este marco, es el Ministerio de Medio Ambiente del Gobierno Nacional quien define los principios generales para la planificación en el área del Gran Copenhague y se asegura de que los 34 municipios de la Región de Copenhague respeten las disposiciones establecidas en el Plan de los Dedos dentro de su propia planificación municipal. Por último, el nuevo Plan de los Dedos de 2007, dio capacidad a las autoridades locales para urbanizar dentro de una franja de cuatro kilómetros definida por el Plan, estableciendo claramente el orden en el que se desarrollarán dichas áreas (Brüel, 2012).

\section{IV.3. Los Anillos Verdes de Colonia}

La ciudad alemana de Colonia cuenta con dos Anillos Verdes. Uno de ellos se encuentra integrado en la trama de la ciudad rodeando el núcleo romano y medieval, de $7 \mathrm{~km}$ de longitud y 120 hectáreas de extensión, siendo una de las principales características estructurales de la ciudad. Este Anillo Interior no sólo se utiliza para la organización de los espacios verdes de Colonia, siendo el punto de partida y elemento central de todo el sistema verde urbano, sino que también constituye un espacio de encuentro para los ciudadanos. Precisamente, es muy frecuentado por el lugar central que ocupa en la ciudad dado que sirve de interfaz entre los ciudadanos del interior de la ciudad y los habitantes de los barrios exteriores cercanos. Su origen data del año 1919, con un diseño que pretendía satisfacer las necesidades de parques públicos de la época. Otro pilar sobre el que se ha sustentado y que ha variado su diseño original es el trazado ferroviario existente. Se pretende que el futuro desarrollo y cierre del Anillo favorezca el avance del anillo ferroviario. Se insiste también en conseguir una permeabilidad de la zona verde y que no actúe como frontera que separe la zona central de los barrios periféricos, así como en la flexibilidad de su trazado.

El Anillo Exterior, periférico, ocupa las fortificaciones que fueron abandonadas después del Tratado de Versalles y comprende una superficie en torno a 800 hectáreas. Se trata de una zona boscosa plantada a finales del siglo XIX, que se extiende próxima a los bordes de la ciudad, en el Oeste y Sur de la misma, y que se conservó libre de edificación debido a su uso militar. El proyecto original, planteado en el año 1923, proponía la creación de una zona de fijación al crecimiento de la ciudad constituida por espacios verdes que al mismo tiempo proporcionasen una transición creativa y escalonada en la intensidad de uso entre la zona construida y el paisaje natural. Se pudo llevar a cabo gracias al poder otorgado al Ayuntamiento para la expropiación de terrenos. Asimismo, se planteaba como una medida de creación de empleo en el período de alto desempleo posterior a la Primera Guerra Mundial en el que se llevó a cabo. Contiene extensos terrenos dedicados a zonas de ocio donde el agua para la práctica de deportes acuáticos juega un papel esencial en su diseño, al ser la razón por la que se construyeron ocho cuencas artificiales a lo largo del Cinturón Verde Exterior. Inicialmente, se pretendía el cierre del Anillo por la parte Norte y Este de la ciudad, pero la Gran Depresión, primero, y la II Guerra Mundial, después, impidieron que el proyecto se pudiese concluir.

En la actualidad, a través del programa Regionale 2010, que se encuentra en pleno desarrollo, se ha proyectado conectar ambos anillos con los grandes sistemas naturales de ámbito regional, creando una red funcional de sistemas verdes. En 2012, se redactó el Plan Estraté- 
gico “Anillo Verde: Impulso 2012" que dio como fruto un plan general para la reurbanización de la zona verde con el objetivo de mejorar la capacidad de uso del cinturón verde por parte de la ciudadanía y su accesibilidad. Este plan ha contado con una amplia participación ciudadana con la pretensión de recuperar el cinturón verde exterior como parque recreativo y de ocio para los habitantes de las zonas residenciales adyacentes, y también para toda la ciudad. En el proceso de su elaboración, se puso en marcha un Taller de Participación Ciudadana para sondear la opinión de diferentes asociaciones culturales, deportivas y medioambientales de la ciudad y luchar contra el deterioro de la percepción de la utilidad del anillo derivado de los cambios que en él se están originando como consecuencia del desarrollo del trazado ferroviario. De hecho, entre los potenciales impactos señalados destaca las fuertes presiones del creciente número de infraestructuras de transporte que hacen peligrar la conectividad de la zona (ver Figura 3).

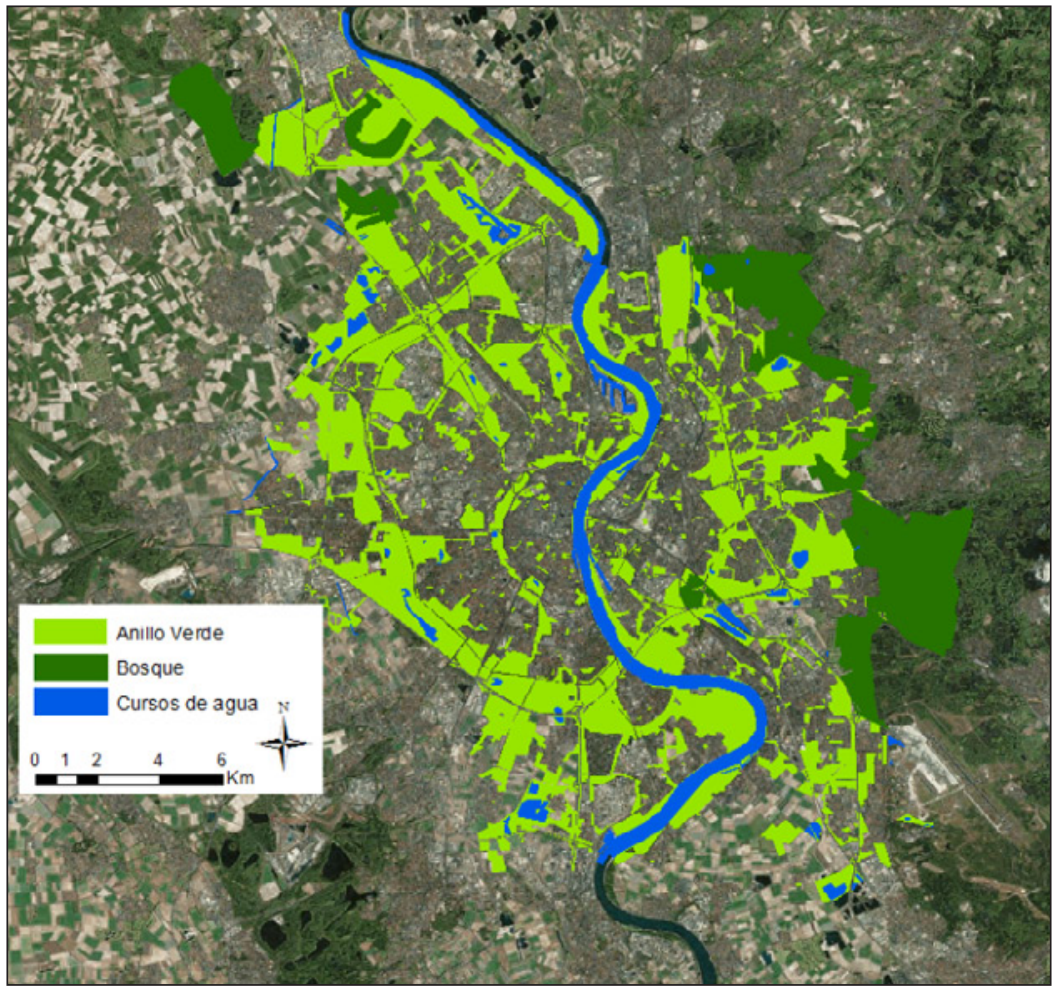

Fuente: elaboración propia mediante ARCGIS.

Los objetivos principales que persigue este anillo son los de preservación de las características ecológicas de la zona y la dotación de espacios verdes y zonas de recreo a la ciudad. Además, estos espacios cumplen una serie de funciones ecológicas y climatológicas muy valiosas. 
En este sentido, el Servicio Forestal creó en 2010, gracias al patrocinio de empresas privadas, un Centro de Investigación para el desarrollo de bosques de cara a la lucha contra el cambio climático. También, gracias a donaciones particulares que alcanzaron la cifra de 370.000 euros, a través del programa denominado "1000 bancos para Colonia" puesto en marcha desde el verano de 2007 por la Fundación Colonia Verde, se ha equipado con bancos y papeleras algunas zonas del Anillo interior y exterior así como las conexiones radiales y jardines de Colonia.

Como aspecto positivo, se podría destacar que al tener una morfología bastante próxima a una red verde, en la que también se integran los cursos de agua, favorece una mayor proximidad y accesibilidad de las zonas verdes a la ciudadanía. Es previsible que su tendencia natural sea la de constituir una completa infraestructura verde en la que se integren las áreas naturales constituidas principalmente por zonas boscosas, junto con los parques urbanos y el sistema hidrológico, buscando una mayor conectividad entre todos estos sistemas.

\section{IV.4. El Anillo Verde de Frankfurt}

Consiste en un amplio espacio de zonas verdes que cubre casi un tercio de la ciudad de Frankfurt, con una superficie de cerca de 8.000 hectáreas, de las cuales alrededor de la mitad son bosque. Aunque quedó aprobado por el gobierno local en 1991, sus orígenes se remontan a la década de 1920, cuando ya se planteaba la idea de proteger un espacio verde para la conservación del medio ambiente y como un elemento separador entre la ciudad central y los nuevos asentamientos periféricos. En 1978, el arquitecto y urbanista Till Behrens desarrolló un concepto inicial del Anillo Verde de Frankfurt, que sirvió de base para que a partir de 1989 el Consejo de la Ciudad iniciase un proyecto de cara a establecer los objetivos de espacios verdes para la ciudad.

Finalmente, en 1991, fue aprobada por unanimidad la constitución del Anillo Verde de Frankfurt con el objeto de establecer un cinturón de espacios abiertos en torno a la ciudad y preservar la fauna y flora de áreas naturales que estaban siendo amenazadas por el desarrollo urbano, protegiendo al mismo tiempo el suministro de agua subterránea. Se constituyó a través de dos documentos estratégicos: el documento Constitución del Anillo Verde, que estableció el conjunto de planes y procedimientos para su desarrollo, y la Carta del Anillo Verde, que contiene los principios y orientaciones para la conservación, gestión y planificación de la zona. Su gestión ha sido delegada a la empresa municipal Green Belt Frankfurt Ltd. En la Conferencia Hábitat II de las Naciones Unidas, celebrada en Estambul en el año 1996, fue destacada como buena práctica de desarrollo urbano sostenible.

Asimismo, 1997 constituye una fecha trascendental porque a través de un proyecto basado en la cooperación interinstitucional se decidió dar un impulso a estas zonas de la ciudad y establecer los principios generales para el diseño de la zona verde a partir de pequeñas intervenciones que se han ido implementando en los años siguientes (la creación del paseo marítimo en las dunas de Schwanheimer, la transformación del antiguo campo de aviación, el rediseño del antiguo cementerio judío de Bergen, etc.). Además, se fijaron 75 lugares singulares en base a su carácter histórico/cultural o de alto valor medioambiental, para regular de forma más estricta sus potenciales usos. También se desarrolló una importante labor para dar a conocer y publicitar el Anillo Verde a través de programas de sensibilización y educación ambiental, la creación de una página web, la publicación de folletos divulgativos, etc. 
Una de sus principales características es la enorme variedad de paisajes y la alta diversidad vegetal y animal que posee, constituyendo un microcosmos representativo de los diferentes paisajes de la región de Rhine-Main. Junto con el atractivo natural del Anillo Verde, la alta calidad de sus instalaciones y zonas deportivas y de ocio, le convierten en una de las áreas de recreo más populares de la región. El Anillo Verde constituye un importante pulmón para la ciudad y contribuye a crear un entorno urbano saludable favoreciendo el desarrollo urbano sostenible. En esta línea, se ha construido una red de senderos y rutas ciclistas que lo atraviesan y que, además, conectan a la ciudad con la región próxima. Ésta, es precisamente, una de las futuras líneas de actuación: el avanzar en los enlaces entre las zonas verdes de la ciudad y de la región para mejorar las cualidades ambientales y fomentar al mismo tiempo su función social. Otro punto a mejorar es su protección jurídica y por ello, actualmente se está implementando la designación de la zona verde como área de conservación.

Sus objetivos a medio plazo son la mejora de los accesos, fortaleciendo las conexiones con los espacios verdes interiores de la ciudad y con otros espacios abiertos y áreas recreativas de la región. También, entre las actuaciones que están previstas en un futuro próximo se encuentra la prolongación del Anillo Verde por un área no consolidada así como la recuperación de un antiguo aeródromo militar. Igualmente, el Banco Central Europeo está proyectando ubicar sus nuevas instalaciones en las proximidades (ver Figura 4).

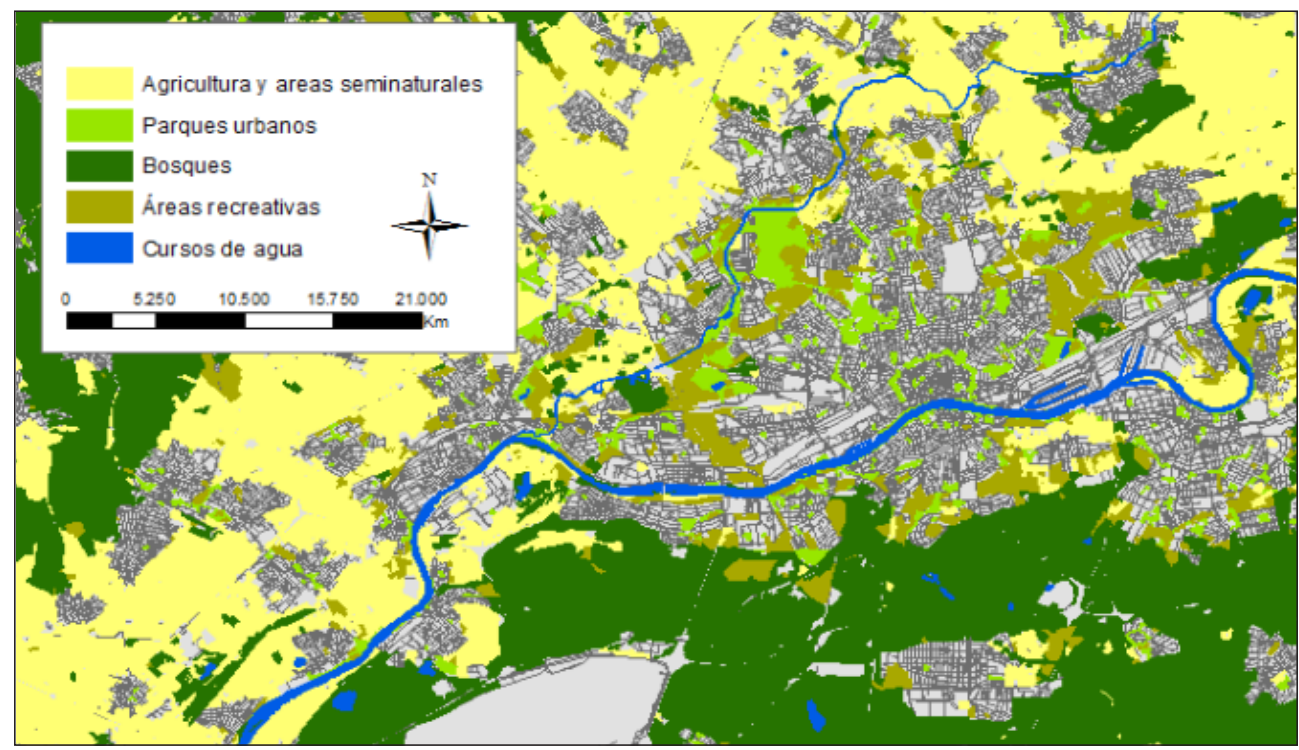

Fuente: elaboración propia mediante ARCGIS en base a información cartográfica del European Urban Atlas.

Aunque no está denominado como tal, Frankfurt cuenta con una serie de parques urbanos interiores construidos donde se localizaba la muralla de la ciudad y que pueden constituirse 
como Anillo Verde interior. Si además se conectase a través de diferentes instrumentos de planeamiento (como itinerarios o sendas verdes), con otros parques urbanos y zonas recreativas se podría conformar una completa infraestructura verde. Por último, la zona también se enfrenta a múltiples problemas como son la contaminación sonora debido a la alta intensidad de tráfico, actuaciones de vandalismo, existencia de vertederos incontrolados, escaso mantenimiento de algunos espacios por falta de presupuesto, etc. Para hacerles frente, el Gobierno Local está articulando una serie de acciones en colaboración con grupos ciudadanos y empresas privadas.

\section{IV.5. La Red Verde y Azul de Bruselas}

La malla verde y azul es un ambicioso proyecto que pretende construir una extensa red de espacios verdes conectados entre sí. Huye, por tanto, de la tradicional forma de anillo circular para buscar una mejor conexión de las diferentes zonas verdes que aglutina. Sus objetivos son satisfacer la demanda de zonas verdes de proximidad, promover la movilidad sostenible facilitando los recorridos de peatones y ciclistas, mejorar la calidad del paisaje urbano, preservar el patrimonio natural y aumentar la biodiversidad. También se presta un especial cuidado a la gestión de las aguas de la ciudad (ver Figura 5). Aún así, existe una senda verde perimetral que hace las funciones de Anillo Verde y representando un espacio de ocio valioso. Su aprovechamiento podría mejorarse, ya que la accesibilidad dada su lejanía al centro urbano no es muy buena y el disfrute de esta área es más esporádico. Cuenta además con importantes áreas naturales de gran valor ecológico incluidas en la Red Natura 2000.

Para mejorar la conectividad, se llevan a cabo actuaciones de plantación de vegetación, mejora de aceras y carriles-bici, acondicionamiento de las riberas de los ríos, etc. con el objetivo de conservar y mejorar la biodiversidad de la ciudad. Se pretende conseguir que la fauna y vegetación recolonice la ciudad al favorecer el tránsito de las diferentes especies de un espacio verde a otro. Los ciudadanos también pueden contribuir con acciones concretas como la creación de "fachadas verdes" y "tejados verdes" o la plantación de árboles en sus jardines privados. Por ello, junto con los parques, que son los elementos más visibles y funcionales de la malla verde, se incorporan otros espacios como lugares abandonados, terraplenes próximos a las vías del tren, jardines verticales en fachadas, techos ajardinados, etc., que contribuyen a dar una mayor continuidad a la red (Kempeneers, 2001).

Con el fin de garantizar una distribución más equitativa de las áreas verdes y fortalecer los corredores ecológicos entre éstas, se aprobó en 2003 un Plan de Desarrollo Regional que prevé el desarrollo gradual de una "Red Verde y Azul" alrededor de la ciudad de Bruselas. El Plan de Desarrollo Regional (PDR) describe el escenario ideal para Bruselas en términos de áreas ecológicas tanto hidrológicas como áreas verdes a conservar (Sundseth y Raeymaekers, 2006). Sin embargo, no se trata de un instrumento jurídicamente vinculante, lo que supone una importante debilidad, puesto que sólo el Plan Régional d'Affectation du Sol (PRAS), que no contiene objetivos tan ambiciosos como el PDR, es legalmente vinculante. No obstante, pretende ejercer una fuerte influencia sobre las propuestas de desarrollo de la Región Metropolitana de Bruselas en lo relativo a la calidad del medio ambiente, el desarrollo sostenible, la solidaridad y la identidad plural de la ciudad, ofreciendo claras orientaciones en cuanto al desarrollo futuro de la región que puedan ser consideradas por las autoridades competentes a la hora de planificar nuevas actuaciones urbanizadoras. 
La Red Verde conecta las zonas verdes con el fin de mejorar la distribución espacial de los espacios naturales y proteger y desarrollar las continuidades entre ellos, de cara a conformar una red de espacios verdes conectados y funcionales tanto desde el punto de vista ecológico como social. Por su parte, la Red Azul pretende mejorar las condiciones de las zonas hidrológicas, tratando de garantizar la continuidad de la red hidrológica en superficie y la calidad del agua en ríos, lagos, pantanos y humedales, recuperando su función ecológica y social.

De cara a la consecución de todo ello, se han llevado a cabo un gran número de actuaciones dirigidas a la restauración de los cauces de los ríos, a la recuperación de lagunas y humedales, a la creación de paseos en el entorno de ríos, a la gestión ecológica activa de estanques y lagos, a evitar la acumulación de restos vegetales en lo cauces y orillas de los ríos, etc. Otra de las iniciativas busca hacer frente a la sobrecarga de los sistemas de recolección de aguas residuales. Muchas de las fuentes de la ciudad al mismo están conectadas al mismo con el consiguiente riesgo de inundaciones. En este sentido, se están haciendo esfuerzos muy importantes para separar las aguas residuales del agua potable y disminuir de este modo la cantidad de agua a tratar en la planta de tratamiento de aguas residuales.

\section{LARED VERDE YAZUL DE BRUSELAS}

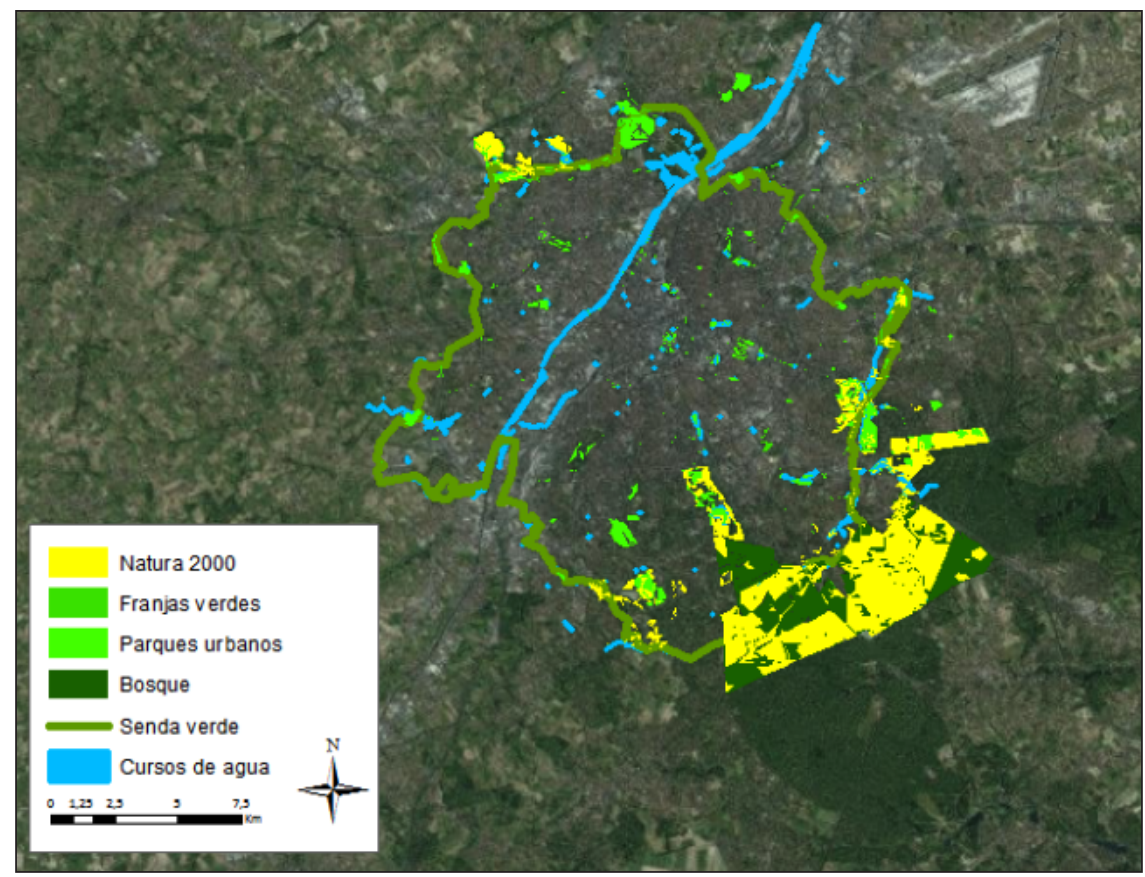

Fuente: elaboración propia mediante ARCGIS en base a información cartográfica del Brussels Regional Informatics Centre

De esta manera, se está construyendo una importante red de espacios ecológicos que está contribuyendo a mejorar la habitabilidad, actuando de pulmón para la ciudad. Ejemplos 
de ello son los trabajos realizados en la zona de Woluwe, en el Sureste de la ciudad, o los trabajos de restauración que prevén la conexión de la zona de Zavelenberg con el pantano de Ganshoren en el Oeste. Así, gradualmente, la red se está fortaleciendo al incorporar retazos de hábitats verdes y azules (Kempeneers, 2001). Como elemento destacable, cabe destacar la construcción de un recorrido de unos sesenta kilómetros que circunda la ciudad denominado "Promenade verte". Esta ruta circular une los parques urbanos con zonas semi-naturales, reservas naturales y bosques de la segunda corona de la región de Bruselas en un intento de crear una infraestructura verde más amplia.

Además, a pesar de ser una red diseñada desde el gobierno regional, muchas autoridades locales se han implicado notablemente en el proyecto. En concreto, diferentes organismos participan en el proyecto como el Instituto para la Gestión del Medio Ambiente de Bruselas, diversas Autoridades Municipales, el Departamento de Infraestructuras y Transporte, etc. En este sentido, en las actuaciones acometidas se ha dado un alto grado de cooperación interinstitucional.

\section{IV.6. Análisis Comparado}

Algunas de las experiencias de Anillos Verdes que hemos estudiado previamente tienen ya una larga trayectoria. Buena parte de dichos Anillos, fueron concebidos con el objetivo primigenio de preservar los paisajes naturales y establecer una separación definida entre las zonas urbanas y rurales. Con el transcurso del tiempo, el papel que han ido desempeñando ha ido evolucionando y adquiriendo mayor relevancia, concediéndose una gran importancia al uso recreativo de estas zonas y a las funciones ecológicas que pueden proporcionar.

En la siguiente Tabla (véase Tabla 3), se presenta un análisis sintético de los resultados de los cinco estudios de caso analizados, centrándonos en aspectos como el año de constitución, la escala, la superficie, la forma y la función, así como realizando un análisis DAFO (Debilidades-Amenaza-Fortalezas-Oportunidades) de cada caso.

Tabla 3

VALORACIÓN COMPARADA DE LOS ESTUDIOS DE CASO

\begin{tabular}{|l|l|l|l|l|l|}
\hline & \multicolumn{1}{|c|}{ Londres } & \multicolumn{1}{c|}{ Copenhague } & \multicolumn{1}{c|}{ Colonia } & \multicolumn{1}{c|}{ Frankfurt } & \multicolumn{1}{c|}{ Bruselas } \\
\hline Año & $\begin{array}{l}1938 \text { aunque } \\
\text { fnalmente cons- } \\
\text { tituido en 1947. }\end{array}$ & 1947 & $\begin{array}{l}1919 \text { (Anillo } \\
\text { Interior) / 1923 } \\
\text { (Anillo Exterior). }\end{array}$ & 1991 & 2003 \\
\hline Escala & Metropolitana & Metropolitana & Municipal & Municipal & $\begin{array}{l}\text { Metropolitana } \\
\text { (19 municipios) }\end{array}$ \\
\hline Superficie & 484.173 Ha. & 10.900 Ha. & $\begin{array}{l}\text { Anillo Interior: } \\
120 \text { Ha. } \\
\text { Anillo Exterior: } \\
800 \text { Ha. }\end{array}$ & 8.000 Ha. & $\begin{array}{l}\text { Reservas natura- } \\
\text { les: } 150 \text { Ha. } \\
\text { Reservas foresta- } \\
\text { les: } 112 \text { Ha. } \\
\text { Lugares Natura } \\
\text { 2000: } 2.334 \text { Ha. } \\
\text { Zonas verdes } \\
\text { urbanas. }\end{array}$ \\
\hline
\end{tabular}




\begin{tabular}{|c|c|c|c|c|c|}
\hline Forma & $\begin{array}{l}\text { Cinturón Verde } \\
\text { tradicional. }\end{array}$ & Cuñas Verdes. & $\begin{array}{l}\text { Dos cinturones } \\
\text { verdes (el inte- } \\
\text { rior no comple- } \\
\text { tamente cerrado) } \\
\text { y un corredor } \\
\text { fluvial. }\end{array}$ & Cinturón verde. & $\begin{array}{l}\text { Red verde con } \\
\text { vocación de } \\
\text { infraestructura } \\
\text { verde urbana y } \\
\text { regional. }\end{array}$ \\
\hline Función & $\begin{array}{l}\text { Protección del } \\
\text { medio rural. } \\
\text { Contención del } \\
\text { crecimiento } \\
\text { urbano. } \\
\text { Uso recreativo. } \\
\text { Conservación } \\
\text { áreas naturales. }\end{array}$ & $\begin{array}{l}\text { Contención de } \\
\text { la dispersión } \\
\text { urbana. } \\
\text { Favorecer la mo- } \\
\text { vilidad urbana. } \\
\text { Dotación de } \\
\text { áreas verdes. }\end{array}$ & $\begin{array}{l}\text { Organización del } \\
\text { sistema verde } \\
\text { urbano. } \\
\text { Usos recreativos. } \\
\text { Contención del } \\
\text { crecimiento. } \\
\text { Preservación de } \\
\text { las característi- } \\
\text { cas ecológicas. }\end{array}$ & $\begin{array}{l}\text { Preservar el } \\
\text { patrimonio } \\
\text { cultural. } \\
\text { Conservación de } \\
\text { la biodiversidad. } \\
\text { Mejorar el paisa- } \\
\text { je urbano. } \\
\text { Dotación de } \\
\text { áreas recreativas. } \\
\text { Promover la } \\
\text { movilidad soste- } \\
\text { nible. }\end{array}$ & $\begin{array}{l}\text { Gestión hidro- } \\
\text { lógica. } \\
\text { Mejorar la bio- } \\
\text { diversidad de la } \\
\text { ciudad. } \\
\text { Fortalecer los } \\
\text { corredores eco- } \\
\text { lógicos. } \\
\text { Mejorar la habi- } \\
\text { tabilidad. }\end{array}$ \\
\hline Debilidades & $\begin{array}{l}\text { Poca implicación } \\
\text { ciudadana. }\end{array}$ & $\begin{array}{l}\text { No existe protec- } \\
\text { ción específica } \\
\text { para los paisajes } \\
\text { agrícolas. } \\
\text { Relajación en } \\
\text { la limitación a } \\
\text { la hora de urba- } \\
\text { nizar. }\end{array}$ & $\begin{array}{l}\text { Deterioro en } \\
\text { la percepción } \\
\text { ciudadana de su } \\
\text { utilidad. }\end{array}$ & $\begin{array}{l}\text { Conflictos entre } \\
\text { el uso recreativo } \\
\text { y el uso agrícola. } \\
\text { Degradación de } \\
\text { algunos espacios } \\
\text { por falta de } \\
\text { presupuesto. }\end{array}$ & $\begin{array}{l}\text { No se dispone de } \\
\text { un instrumento } \\
\text { legal jurídica- } \\
\text { mente vincu- } \\
\text { lante. }\end{array}$ \\
\hline Amenazas & $\begin{array}{l}\text { Presión urbanís- } \\
\text { tica. } \\
\text { Construcción de } \\
\text { infraestructuras. }\end{array}$ & $\begin{array}{l}\text { Declive de las } \\
\text { tierras de cultivo. } \\
\text { Presión urbanís- } \\
\text { tica. }\end{array}$ & $\begin{array}{l}\text { Creciente } \\
\text { número de in- } \\
\text { fraestructuras de } \\
\text { transporte. }\end{array}$ & $\begin{array}{l}\text { Falta de civismo } \\
\text { por parte de } \\
\text { algunos ciuda- } \\
\text { danos. } \\
\text { Contaminación } \\
\text { acústica del } \\
\text { Aeropuerto. }\end{array}$ & $\begin{array}{l}\text { Sobrecarga de } \\
\text { los sistemas de } \\
\text { recolección de } \\
\text { aguas y gestión } \\
\text { de inundaciones. }\end{array}$ \\
\hline Fortalezas & $\begin{array}{l}\text { Buena preserva- } \\
\text { ción de los usos } \\
\text { agrícolas. } \\
\text { Alta protección } \\
\text { del suelo. }\end{array}$ & $\begin{array}{l}\text { Gestión en } \\
\text { coherencia con } \\
\text { la movilidad. }\end{array}$ & $\begin{array}{l}\text { Impulso de la } \\
\text { participación } \\
\text { ciudadana. } \\
\text { Permeabilidad de } \\
\text { la zona verde. } \\
\text { Proximidad y } \\
\text { alta frecuenta- } \\
\text { ción del Anillo } \\
\text { Verde Interior. }\end{array}$ & $\begin{array}{l}\text { Impulso de la } \\
\text { sensibilización y } \\
\text { educación } \\
\text { ambiental. } \\
\text { Impulso de la } \\
\text { accesibilidad. } \\
\text { Dispone de } \\
\text { una legislación } \\
\text { específica. }\end{array}$ & $\begin{array}{l}\text { Estrecha coope- } \\
\text { ración interinsti- } \\
\text { tucional. }\end{array}$ \\
\hline Oportunidades & $\begin{array}{l}\text { Posibilidad de } \\
\text { crear una red } \\
\text { verde con la } \\
\text { construcción de } \\
\text { corredores eco- } \\
\text { lógicos }\end{array}$ & $\begin{array}{l}\text { Su flexibilidad } \\
\text { para adaptarse al } \\
\text { crecimiento de la } \\
\text { ciudad. }\end{array}$ & $\begin{array}{l}\text { Posibilidad de } \\
\text { unir ambos Ani- } \\
\text { llos con sistemas } \\
\text { naturales de la } \\
\text { región. } \\
\text { La recuperación } \\
\text { del cinturón ver- } \\
\text { de exterior como } \\
\text { parque recreativo } \\
\text { y de ocio. }\end{array}$ & $\begin{array}{l}\text { Mejora de los } \\
\text { accesos. } \\
\text { Conexión con } \\
\text { las zonas verdes } \\
\text { interiores de la } \\
\text { ciudad. } \\
\text { Su futura exten- } \\
\text { sión. }\end{array}$ & $\begin{array}{l}\text { La recuperación } \\
\text { e integración de } \\
\text { espacios degra- } \\
\text { dados interiores } \\
\text { de la ciudad. }\end{array}$ \\
\hline
\end{tabular}

Fuente: elaboración propia. 
Como se ha podido observar, existen una serie de factores recurrentes en las diferentes experiencias de Anillos Verdes: su capacidad de evolucionar para hacer frente a las necesidades actuales de la sociedad, las tensiones generadas debido a la continua presión del crecimiento urbano y las infraestructuras asociadas, la importancia del apoyo activo por parte de los propietarios de las tierras, la relevancia de que existan instrumentos legales de planificación y gestión, el potencial para la restauración y mejora de los espacios naturales, la coherencia que debe guardar con otro tipo de políticas como la gestión hidrológica o la movilidad, y el creciente compromiso ciudadano o la necesidad de él.

Este compromiso se puede contemplar en algunos casos en relación a la financiación, que aunque, fundamentalmente proviene de los Gobiernos Locales, en los últimos años y cada vez con más frecuencia, se están realizando campañas para recibir donaciones particulares o de empresas sobre todo relacionadas con la dotación de infraestructuras y equipamientos o con la plantación de árboles. Precisamente, la limitación de presupuesto es uno de los principales retos a los que se deben enfrentar estas áreas ya que, a menudo, suele dar lugar a problemas de mantenimiento y de degradación, incrementándose, en numerosas ocasiones, los efectos negativos por una mala gestión de su uso o por comportamientos incívicos por parte de los ciudadanos.

En esta línea, la gestión del uso de estos espacios se erige como un elemento fundamental para su conservación, puesto que un uso excesivo de los mismos puede entrar en conflicto con la conservación de la biodiversidad y de los usos agrícolas. De este modo, aunque en buena parte de los casos, se están desarrollando iniciativas que fomenten la accesibilidad, sin olvidar que la preservación de las funciones ecológicas es una de las razones fundamentales para su creación, en otros casos, se están planteando la posibilidad de restringir su acceso o limitar su uso a determinadas zonas.

En cuanto a la funcionalidad real de los Anillos Verdes, al margen de los objetivos primigenios de estas iniciativas, podemos ver que existe una variedad de casuísticas en los ejemplos analizados. Así, el Anillo Verde de Londres, cuya designación es la más antigua, es un ejemplo de actuación poco intervencionista, donde se ha primado la planificación física de un instrumento que actúa de contención. Algo similar, ocurre con el caso de Copenhague, donde fundamentalmente se ha utilizado para encauzar el crecimiento de la ciudad, aunque también cuente con extensas áreas de conservación incluidas en la red Natura 2000. En Bruselas, Frankfurt y Colonia, por el contrario, se persiguen en mayor medida objetivos ecológicos y de conservación de la biodiversidad, así como el intentar dar coherencia al sistema verde urbano conectándolo con el sistema regional. Pero, también se debe señalar que en todos los casos, se pretende alcanzar el objetivo social de establecer áreas recreativas para los ciudadanos de mayor o menor proximidad y en entornos con diferentes grados de intervención (desde bosques naturales hasta parques urbanos).

Por otra parte, la propiedad de la tierra de esta zonas no es siempre de titularidad pública, por lo que la cooperación y el buen entendimiento por parte de la Administración con los propietarios privados, generalmente pequeños agricultores, es fundamental. Además, una de las funciones de estos espacios es proteger los usos agrícolas de la tierra, por lo que se deberían desarrollar programas específicos que potencien esa agricultura de proximidad como podría ser, por ejemplo, la creación de mercados de venta de productos locales, ayudas para transformar la actividad en agricultura ecológica, creación de espacios de huertas 
públicas dedicados a crear empleo con fines de inserción social de determinados colectivos o simplemente como una actividad programada de ocio, etc. Además, la potenciación del uso agrícola puede incrementar las rentas de los agricultores debido a la mayor proximidad a los clientes, que valoran una mayor transparencia en las prácticas agrícolas y en el origen de los alimentos, sobre todo si se fomentan las ventas directas, ya que los canales de distribución directa permiten a los agricultores un mayor control sobre los precios y un mayor margen de beneficio (Akimowicz et al., 2016).

En cuanto a la forma, se puede observar que varios Anillos Verdes se configuran siguiendo el enfoque tradicional, como una frontera entre la ciudad central y las comunidades suburbanas. En cierto sentido, son concepciones abstractas que se plasman sobre el territorio y que no siempre se ajustan del todo a los parámetros paisajísticos (Yang y Jinxing, 2007). También podríamos decir que muchas veces se plantean como estructuras que dan la espalda a los núcleos rurales próximos. Sin embargo, con esta primera interpretación no se consideran los flujos y las interrelaciones entre las zonas urbanas y rurales, olvidando que los Anillos Verdes podrían cumplir un papel importante en la estructuración de las regiones urbanas actuando como conectores de las distintas unidades espaciales (Kühn, 2003).

Por ello, muy probablemente el futuro de los Anillos Verdes esté ligado a su evolución hacia completas infraestructuras verdes con el desarrollo y la protección de una red multifuncional de espacios verdes junto con la adecuada gestión de la red hidrográfica de las áreas urbanas (Schrijnen, 2000). Esto permitirá, en mayor medida una mejor conservación de la biodiversidad, una mejora de la conectividad, una mayor resiliencia ecológica de las áreas naturales y un mayor grado de funcionalidad del ecosistema en el suministro de bienes y servicios (AEMA; 2011, Aguado et al., 2013). Se trata de introducir la biodiversidad en la ciudad como se está haciendo, por ejemplo, en el caso de Bruselas a través de instrumentos tales como "fachadas verdes", "tejados verdes", jardines privados, etc., recuperando cualquier espacio susceptible de contener biodiversidad.

\section{CONCLUSIONES}

Podemos afirmar que infraestructuras como los Anillos Verdes resultan vitales para la conservación del suelo natural y la preservación de las especies autóctonas. Es aquí donde radica uno de sus principales ventajas pensando, sobre todo, en las necesidades de las generaciones futuras. Mediante la correcta gestión de este tipo de infraestructuras verdes se puede preservar el patrimonio natural y cultural, encaminándonos hacia un modo de vida más sostenible.

La revisión de los resultados de los diferentes casos, sugiere que los planificadores de este tipo de iniciativas en el futuro deberían: (1) determinar su forma, función y organización conceptual poniendo el énfasis en la conectividad y en la protección de los sistemas naturales y las cualidades culturales, (2) aplicar los principios de sostenibilidad con el fin de mantener la biodiversidad, el funcionamiento del sistema y la productividad, adaptándola a los niveles apropiados de uso humano, (3) formular estrategias de implementación y gestión que sean eficientes y asequibles y (4) reunir apoyo público informando e involucrando a la ciudadanía local (Taylor et al., 1995). 
En este sentido, consideramos que el ciudadano juega un papel fundamental en el éxito de estas iniciativas. Por ello, uno de los factores en los que principalmente se incide, en todos los casos, es en la necesidad de un alto grado de apoyo social como elemento esencial para el éxito a largo plazo de los anillos verdes y para defenderlos frente a presiones inmobiliarias. Para fomentar este apoyo, es necesaria una comunicación fluida y constante acerca de los beneficios que se derivan de su desarrollo. La puesta en marcha de proyectos tales como la implementación de un sistema de senderos y caminos o de centros e instalaciones de interpretación de la naturaleza contribuyen a crear y mantener ese apoyo. También, aunque podamos considerarlo como no relevante, la señalética y la simbología para identificar los espacios que conforman los Anillos Verdes es un aspecto crucial al que diversas autoridades locales (por ejemplo, Frankfurt) han concedido notable importancia.

Otro aspecto reseñable es el de la permeabilidad para los diferentes usos. Un Anillo Verde no debería actuar de frontera infranqueable y tampoco limitar de forma crucial la necesidad de futuros desarrollos urbanísticos. Una de las críticas que se suele realizar a este tipo de planificación es que pueden contribuir al encarecimiento del precio de la vivienda. Por ello, su diseño tiene que ser lo suficientemente flexible, realista y consciente de las previsiones de crecimiento poblacional para poder permitir una dotación adecuada de viviendas. Pero, al mismo tiempo, se debe intentar conservar lo menos urbanizado posible, reduciendo al mínimo las infraestructuras y disminuyendo las barreras artificiales cuando ya existan. Es importante entender la oportunidad de preservar estas áreas como zonas a incluir en la red Natura 2000, para otorgarles una mayor protección ambiental.

Es complicado predecir qué papel desempeñarán los Anillos Verdes en el futuro. Lo que sí podemos constatar es que, a pesar de que los primeros Anillos Verdes se gestaron con el ánimo de proteger paisajes con características ambientales que en su momento podían pasar desapercibidas, hoy son altamente valorados. Del mismo modo, es probable que los Anillos Verdes constituidos más recientemente adquieran una importancia creciente para las comunidades locales a la vista de los cambios globales que están aconteciendo, como los impactos generados por el cambio climático, la escasez de agua o el encarecimiento de las materias primas. Un gran reto será el favorecer su transición hacia infraestructuras verdes en red. En este aspecto los espacios interiores en desuso o vacíos pueden jugar un papel primordial. En la medida de lo posible, se debe debatir los artificios legales para transformar muchos de estos espacios interiores en áreas de oportunidad para su aprovechamiento como espacios públicos de calidad.

Finalmente, añadir que existen algunas funciones a las que, en el ámbito europeo, no se les está concediendo la importancia que merecen como por ejemplo la posibilidad de fomentar una agricultura sostenible en entornos próximos a las zonas urbanas. En este sentido, puede afirmarse que los movimientos de Local Food no han calado tan fuertemente en Europa como en otros países, como los Estados Unidos o Canadá. Otro reto al que tendrán que enfrentarse los gobiernos es a la gestión del uso de estos espacios ya que se está primando en gran medida su uso recreativo, lo que entra en serio conflicto con la conservación de algunas especies. Aunque, por contra, se corre el riesgo de una gentrificación del ocio en estos espacios si no se gestiona su accesibilidad dado que con frecuencia se encuentran alejados del núcleo urbano y no toda la población tiene facilidades para acceder a los mismos. Será, por tanto, necesario encontrar un equilibrio entre el acceso público y la conservación y preservación biológica de estas zonas. 


\section{REFERENCIAS}

AEMA, Agencia Europea del Medio Ambiente (2011): Green infrastructure and territorial cohesion. The concept of green infrastructure and its integration into policies using monitoring systems. EEA Technical Report, $\mathrm{n}^{\mathrm{o}}$ 18. Luxemburgo: Oficina de publicaciones de la Unión Europea. Disponible en http://www.eea.europa.eu/es

AGUADO, I, BARRUTIA, J.M. y ECHEBARRIA, C. (2013): "The green belt of VitoriaGasteiz. A successful practice for sustainable urban planning”. Boletín de la Asociación de Geógrafos Españoles, $\mathrm{n}^{\circ}$ 61, 181-193.

AHERN, J. (2007): “Green Infrastructure for Cities: The Spatial Dimension” en V. Novotny, P. Brown. (eds.), Cities of the Future: Towards integrated sustainable water and landscape management. London, IWA Publishing, 267-283.

AKIMOWICZ, M., CUMMINGS, H. y LANDMAN, K. (2016). "Green lights in the greenbelt? A qualitative analysis of farm investment decision-making in peri-urban southern Ontario". Land Use Policy, n 55, 24-36.

ALI, A.K. (2008): "Greenbelts to contain urban growth in Ontario, Canada: Promises and prospects". Planning Practice and Research, vol. 23, n 4, 533-548.

AMATI, M. (2007): "From a blanket to a patchwork: the practicalities of reforming the London green belt". Journal of Environmental Planning and Management, vol. 50, $\mathrm{n}^{\circ} 5$, 579-594.

AMATI, M. y YOKOHARI, M. (2006): "Temporal changes and local variations in the functions of London's green belt". Landscape and Urban Planning, vol. 75, $\mathrm{n}^{\circ}$ 1-2, 125-142.

AMATI, M. y YOKOHARI, M. (2007): “The establishment of the London Greenbelt: Reaching consensus over purchasing land". Journal of Planning History, vol. 6, $\mathrm{n}^{\mathrm{o}} 4$, 311-337.

BENEDICT, M.A. y McMAHON, E.T. (2002): Green Infrastructure: Smart Conservation for the 21st Century. Washington: The Conservation Fund.

BENEDICT, M.A. y McMAHON, E.T. (2006): Green Infrastructure: linking landscapes and communities. Washington: Island Press.

BENGSTON, D.N. (2005): "An analysis of the public discourse about urban sprawl in United States: monitoring concern about a major threat to forests". Forest Policy and Economics, vol. 7, $\mathrm{n}^{\circ}$ 5, 745-756.

BENGSTON, D.N. y YOUN, Y.C. (2006): "Urban containment policies and the protection of natural areas: the case of Seoul's greenbelt". Ecology and Society, vol. 11, n 1, art. 3. Disponible en http://www.ecologyandsociety.org/vol11/iss1/art3/

BILES, R. (1998): "New towns for the Great Society: a case study in politics and planning". Planning Perspectives, vol. 13, $\mathrm{n}^{\circ}$ 2, 113-132.

BLAIS, P. (2010): Perverse cities. Hidden subsidies, wonky policy and urban sprawl. Vancouver (Canada), UBC Press.

BLINNIKOV, M., SHANIN, A., SOBOLEV, N. y VOLKOVA, L. (2006): “Gated communities of the Moscow green belt: newly segregated landscapes and the suburban Russian environment". GeoJournal, vol. 66, 65-81. 
BRABEC, E. y LEWIS, G. (2002): “Defining the Pattern of the Sustainable Urban Region" en The sustainable city II. Urban regeneration and sustainability (Brebbia, C.A., MartínDuque, J.F. y Wadhwa, L.C., eds.). Southampton, WIT Press, 487-496.

BREILING, M. y RULAND, G. (2008): “The Vienna Green Belt: From Localised Protection to a Regional Concept", en Urban Green Belts in the Twenty first Century (Amati, ed.). London: Ashgate, 167-185.

BROWN, D.G., PAGE, S.E., RIOLO, R. y RAND, W. (2004): “Agent-based and analytical modelling to evaluate the effectiveness of greenbelts". Environmental Modelling \& Software, vol. 19, $\mathrm{n}^{\mathrm{o}}$ 12, 1097-1109.

BRÜEL, M. (2012): “Copenhagen, Denmark: Green City amid the Finger Metropolis" en Green Cities of Europe (Beatley, T., Ed.). Washington, etc., Island Press, 83-108.

BURTON, E. (2000): "The Compact City: Just or Just Compact? A Preliminary Analysis". Urban Studies, vol. 37, n 11, 1969-2001.

CAMPBELL, M. O. (2009): "The impact of habitat characteristics on bird presence and the implications for wildlife management in the environs of Ottawa, Canada". Urban Forestry \& Urban Greening, vol. 8, 87-95

CARTER-WHITNEY, M. y ESAKIN, T.C. (2010): Ontario's Greenbelt in an International Context. Toronto, The Canadian Institute for Environmental Law and Policy. Disponible en http://cielap.org/pdf/GreenbeltInternationalContext2010.pdf

CASADO-ARZUAGA, I., MADARIAGA, I. y ONAINDIA, M. (2013). "Perception, demand and user contribution to ecosystem services in the Bilbao metropolitan greenbelt". Journal of Environmental Management, $\mathrm{n}^{\circ}$ 129, 33-43.

CASPERSEN, O.H. y OLAFSSON, A.S. (2010): "Recreational mapping and planning for enlargement of the green wedges in Greater Copenhagen". Urban Forestry and Urban Greening Greening, vol. 9, 101-112.

COHEN, S.E. (1994): "Greenbelts in London and Jerusalem". Geographical Review, vol. 84, $\mathrm{n}^{\mathrm{o}}$ 1, 74-89. Disponible en http://www.jstor.org/stable/215782

COMISIÓN EUROPEA (1990): Libro Verde sobre el Medio Ambiente Urbano. Bruselas, Comunicación de la Comisión al Consejo y al Parlamento Europeo.

COMISIÓN EUROPEA (2009): Towards a green infrastructure for Europe: Integrating Natura 2000 sites into the wider countryside. Proceedings of the European Commission workshop. Bélgica: Oficina de publicaciones de la Unión Europea.

COX, W. (2004). Myths about Urban Growth and the Toronto "Greenbelt". Fraser Institute Digital Publication. Disponible en http://www.demographia.com/db-torgreenbelt.pdf

DAWKINS, C.J. y NELSON, A.C. (2002): "Urban containment policies and housing prices: an international comparison with implications for future research". Land Use Policy, vol. $19, \mathrm{n}^{\circ} 1,1-12$.

DEATON, B. y VYN, R.J. (2010): “The Effect of Strict Agricultural Zoning on Agricultural Land Values: The Case of Ontario's Greenbelt”. American Journal of Agricultural Economics, vol. 92, n 4, 941-955.

EVANS, A. W. (2006). "Planificación, cinturones verdes y límites al crecimiento urbano", en Santiago. Dónde estamos y hacia dónde vamos (Galetovic, A., ed.). Santiago, Centro de Estudios Público, 186-188. 
FREESTONE, R. (2002): "Greenbelts in City and Regional Planning", en From Garden City to Green City: The Legacy of Ebenezer Howard, (Parsons, K. y Schuyler, D., eds.). Baltimore, John Hopkins, 67-98.

HALL, P.H., GRACEY, R., DREWETT, R. y THOMAS, R. (1973): The Containment of Urban England. London: Allen and Unwin.

HOWARD, E. (1898): To-morrow: A Peaceful Path to Real Reform (reimpresión 2010). Cambridge, New York, etc., Cambrigde University Press.

HOWARD, E. (1902): Garden Cities of To-morrow (reimpresión de 2007). Oxon, Routledge. JUN, M. (2012): “The effects of Seoul's greenbelt on the spatial distribution of population and employment, and on the real estate market". The Annals of Regional Science, vol. 49, $\mathrm{n}^{\circ} 3,619-642$. Disponible en http://search.ebscohost.com/login.aspx?direct=true \&db=eo ah\&AN=25323674\&site $=$ ehost-live

KAHN, F.I. y ABBASI, S.A. (2000): “Attenuation of gaseous pollutants by greenbelts". Environmental Monitoring and Assessment, vol. 64, 457-475.

KEMPENEERS, S. (2001): The politics of 'the green network' and 'the blue network' from the regional plan of development. Disponible en http://www.fedenatur.org/docs/ docs/129.pdf

KIM, J. (1990): “Urban redevelopment of green belt villages: A case study of Seoul”. Cities, vol. $7, \mathrm{n}^{\mathrm{o}} 4,323-332$.

KIM, J. y KIM, T.-K. (2008): "Issues with green belt reform in the Seoul metropolitan area", en Urban Green Belts in the Twenty first Century (Amati, ed.). London: Ashgate, 37-59.

KÜHN, M. (2003): "Greenbelt and green heart: separating and integrating landscapes in European city regions". Landscape and Urban Planning, vol. 64, 19-27.

LABIDOIRE, L. (2013): La planificación urbanística de los cinturones verdes: el caso del Anillo Verde de Vitoria-Gasteiz. Trabajo Fin de Máster. Máster Planificación Territorial y Gestión Ambiental. Barcelona, Universidad de Barcelona.

MACDONALD, S. (2012): “The Ontario Greenbelt: Shifting the Scales of the Sustainability Fix?" The Professional Geographer, vol. 64, n 1, 125-145.

MILLS, E.S. (2002): “Government urban growth controls". International Real Estate Review, 5, 1-11.

MILLWARD, H. (2006): "Urban containment strategies: A case-study appraisal of plans and policies in Japanese, British, and Canadian cities". Land Use Policy, vol. 23, nº . 4, 473-485.

MORTBERG, U. y WALLENTINUS, H. (2000): "Red-listed forest bird species in an urban environment and assessment of green space corridors". Landscape and Urban Planning, vol. 50, 215-226.

MUNTON, R. (1983): London's Green Belt containment in practice. London, George Allen \& Uwin.

NATURAL ENGLAND (2010a): Green Belts: a greener future. Natural England, Campaign to Protect Rural England. Disponible en http://www.cpre.org.uk/resources/housing-andplanning/green-belts

NATURAL ENGLAND (2010b): The London (Metropolitan) Green Belt. Natural England, Campaign to Protect Rural England. Disponible en http://www.cpre.org.uk/resources/ housing-and-planning/green-belts 
NATURAL ENGLAND (2011): "Green Belts in England: Key facts", en A series of factsheets on England's 14 Green Belts. Disponible en http://www.cpre.org.uk/resources/housing-and-planning/green-belts/item/1957-green-belts-in-england-key-facts

PENDALL, R., MARTIN, J. y FULTON, W. (2002): Holding the Line: Urban Containment in the United States. Washington, D.C.: Center on Urban and Metropolitan Policy, The Brookings Institution. Disponible en http://www.brookings.edu/ /media/Files/rc/reports/ 2002/08metropolitanpolicy_pendall/pendallfultoncontainment.pdf

RUEDA, S. (2002): Modelos de ordenación del territorio más sostenibles. Barcelona. Disponible en: http://arquiciudad.comoj.com/Archivos.Net/Fase\%20I/S_Rueda/modelosurbanosSost.pdf

SCHRIJNEN, P.M. (2000): "Infrastructure networks and red-green patterns in city regions". Landscape Urban Planning, vol. 48, 191-204.

SIEDENTOP, S., FINA, S. y KREHL, A. (2016). "Greenbelts in Germany's regional plans -An effective growth management policy?". Landscape and Urban Planning, n 145, 71-82.

SORENSEN, A. (2001): “Subcentres and Satellite Cities: Tokyo's 20th Century Experience of Planned Polycentrism". International Planning Studies, vol. 6, n 1, 9-32.

SUNDSETH, K. y RAEYMAEKERS, G. (comp.) (2006): Biodiversity and Natura 2000 in urban areas. A review of issues and experiences of nature in cities across Europe for the Brussels Capital Region. Brussels, Ecosystems LTD. Disponible en http:// www.fedenatur.org/docs/docs/279.pdf

TALLON, A. (2010): Urban regeneration in the UK. Oxon, Routledge.

TAN, K.W. (2006): "A greenway network for Singapore". Landscape and Urban Planning, vol. 76, 45-66.

TANG, B., WONG, S. y LEE, A. K. (2007): “Green belt in a compact city: A zone for conservation or transition?" Landscape and Urban Planning, vol. 79, 358-373.

TAYLOR, J., PAINE, C. y FITZGIBBON, J. (1995): "From greenbelt to greenways: four Canadian case studies". Landscape and Urban Planning, vol. 33, n 1-3, 47-64.

THOMAS, L. y COUSINS, W. (1996): “The Compact City: Successful, Desirable and Achievable?" en The compact city: A sustainable urban form? (Jenks, M. et al., eds.). London: E \& FN Spon, 53-65.

TURNER, T. (2006): “Greenway planning in Britain: recent work and future plans". Landscape and Urban Planning, vol. 76, 240-251.

TZOULAS, K.; KORPELA, K.; VENN, S.; YLI-PELKONEN, V.; KAZMIERCZAK, A.; NIEMELA, J.; JAMES, P. (2007): "Promoting ecosystem and human health in urban areas using Green Infrastructure: A literature review". Landscape and Urban Planning, vol. $81, n^{\circ} 3,167-178$.

VERDAGUER VIANA-CÁRDENAS, C. (2010): "Planificación del desarrollo y preservación de los usos agrícolas en el Gran Londres (Gran Bretaña): Pasos hacia el autoabastecimiento y la agricultura de proximidad en una gran capital europea" en El espacio agrícola entre el campo y la ciudad (VÁZQUEZ, M. y VERDAGUER, C., Dirs.). Disponible en http://habitat.aq.upm.es/eacc/alondres.html\#30.

WATANABE, T., AMATI, M., ENDO, K. y YOKOHARI, M. (2008): “The abandonment of Tokyo's green belt and the search for a new discourse of preservation in Tokyo's suburbs", en Urban Green Belts in the Twenty First Century (Amati, ed.). London, Ashgate, 21-37. 
WEEN, C. (2012): "London, England: A Global and Sustainable Capital City" en Green Cities of Europe (Beatley, T., Ed.). Washington, etc., Island Press, 181-214.

WILLIAMS, K., BURTON, E. y JENKS, M. (Eds.) (2001): Achieving Sustainable Urban Form. London and New York: E \& FN Spon.

YANG, J. y JINXING, Z. (2007): "The failure and success of greenbelt program in Beijing". Urban Forestry \& Urban Greening, vol. 6, n 4, 287-296.

YOKOHARI, M., BROWN, R. D. y TAKEUCHI, K. (1994): “A framework for the conservation of rural ecological landscapes in the urban fringe area in Japan". Landscape and Urban Planning, Vol. 29, 103-116.

YOKOHARI, M., TAKEUCHI, K., WATANABE, T. y YOKOTA, S. (2000): “Beyond greenbelts and zoning: A new planning concept for the environment of Asian megacities". Landscape and Urban Planning, vol. 47, n 3-4, 159-171. 